\title{
Failure investigation of a Kaplan turbine blade
}

\section{Ming Zhang}

\section{David Valentín}

david.valentin@upc.edu

\section{Carme Valero}

Mònica Egusquiza

Eduard Egusquiza

Center for Industrial Diagnostics and Fluid Dynamics (CDIF), Polytechnic University of Catalonia (UPC), Av. Diagonal, 647, ETSEIB, 08028 Barcelona, Spain

${ }^{*}$ Corresponding author.

\section{Abstract}

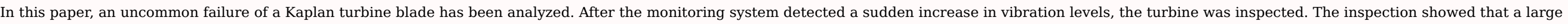

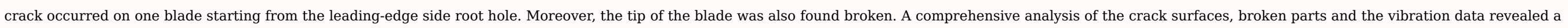
fatigue problem probably caused by rubbing between the blade and the nearby wall.

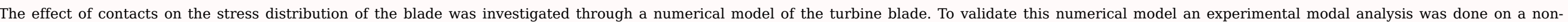

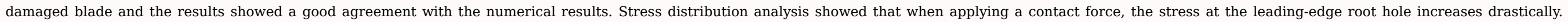
Therefore, experimental evidences as well as numerical simulations confirm that the crack occurred due to rubbing between the blade tip and the nearby wall.

\subsection{Introduction}

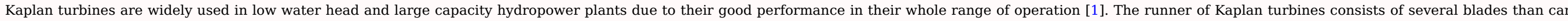

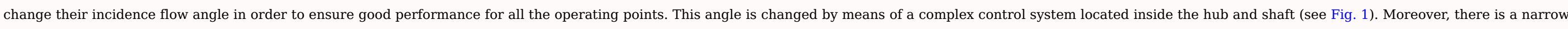

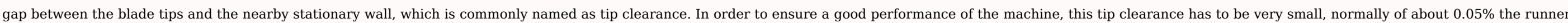
diameter. Details of a typical Kaplan turbine are shown in Fig. 1.

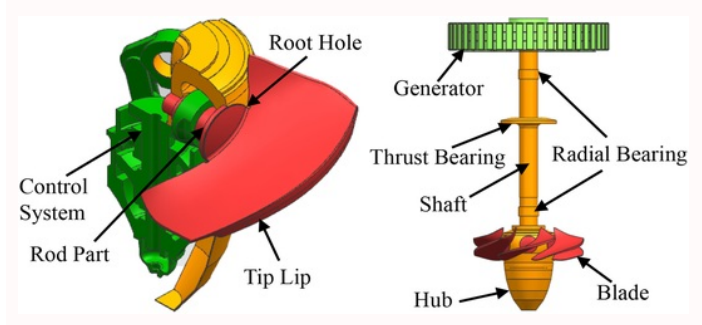

Fig. 1.Fiq. 1 Kaplan turbine assembly

alt-text: Fig. 1 


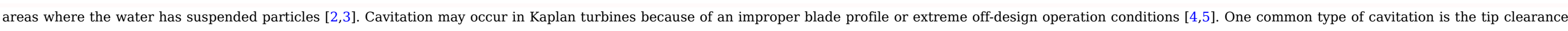

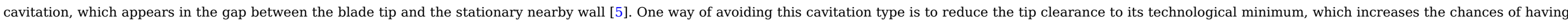

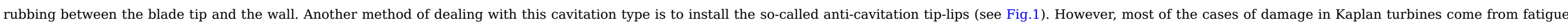
problems [11].

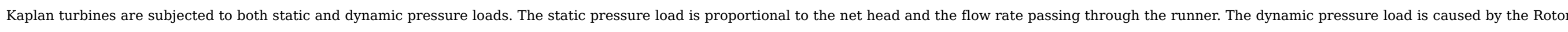

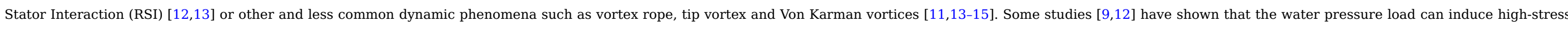

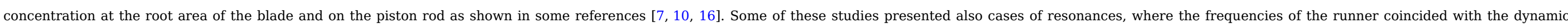

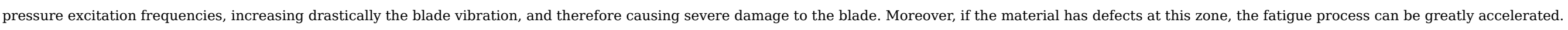

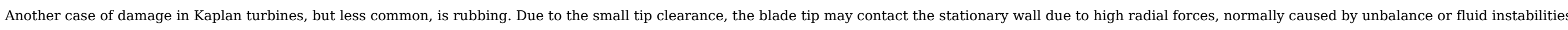

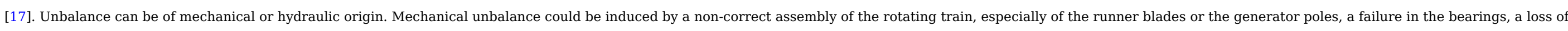

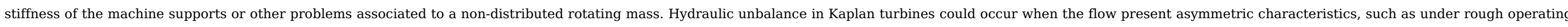

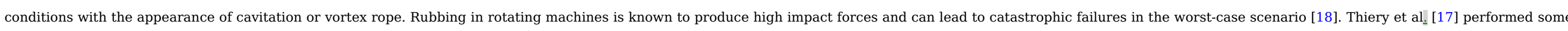

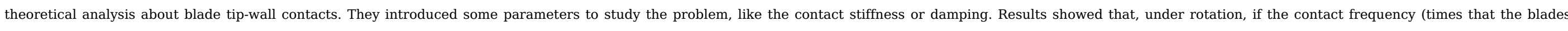

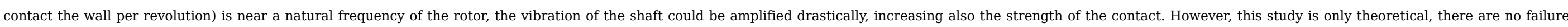
cases of prototype Kaplan turbines due to rubbing available in the literature.

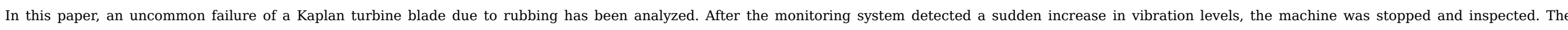

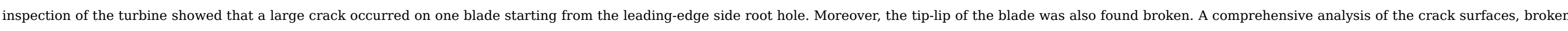

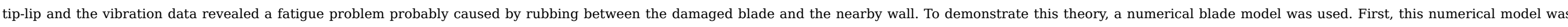

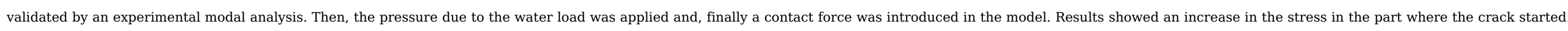
Therefore, both experimental and numerical evidences demonstrate that the crack appeared in the blade due to rubbing between the blade tip and the stationary wall.

\subsection{Damage description}

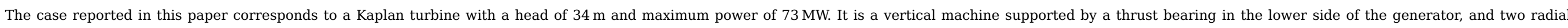

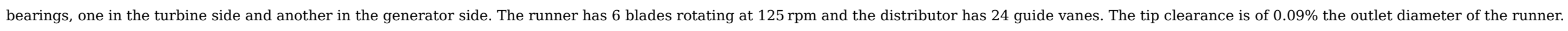

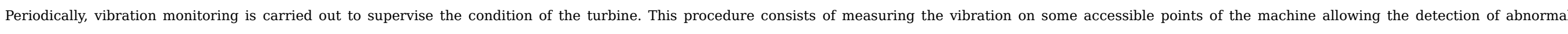

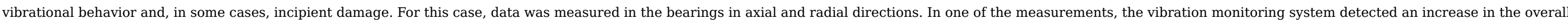
vibration levels, as well as a clear change in the spectra obtained by performing the Fast Fourier Transform (FFT) of the time signal. Therefore, the machine was stopped and inspected.

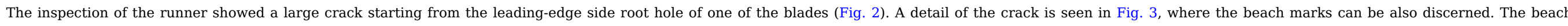

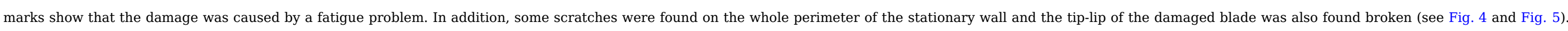

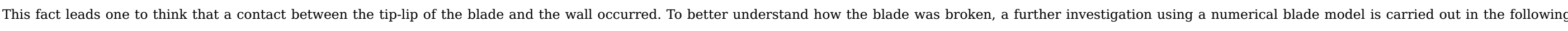
sections. 


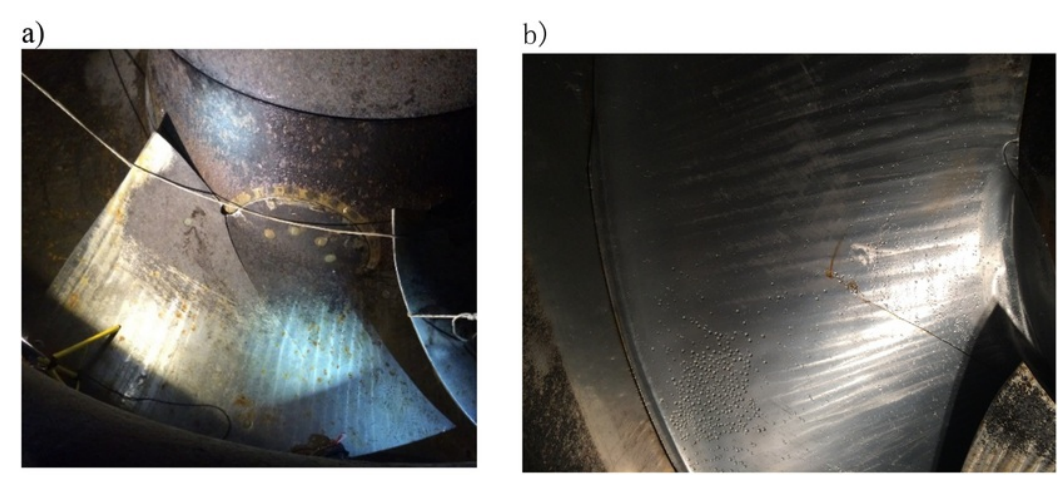

Fig. 2 View of the blade with crack. a) Pressure side. b) Suction side.

alt-text: Fig. 2

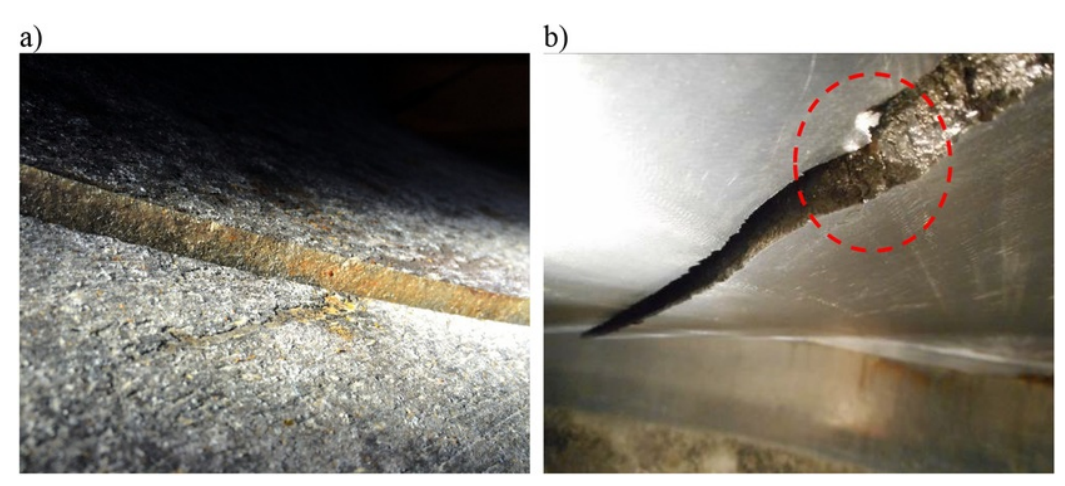

Fig. 3.Fig. 3 Detail of the crack. a) From the pressure side. b) From the suction side.

alt-text: Fig. 3

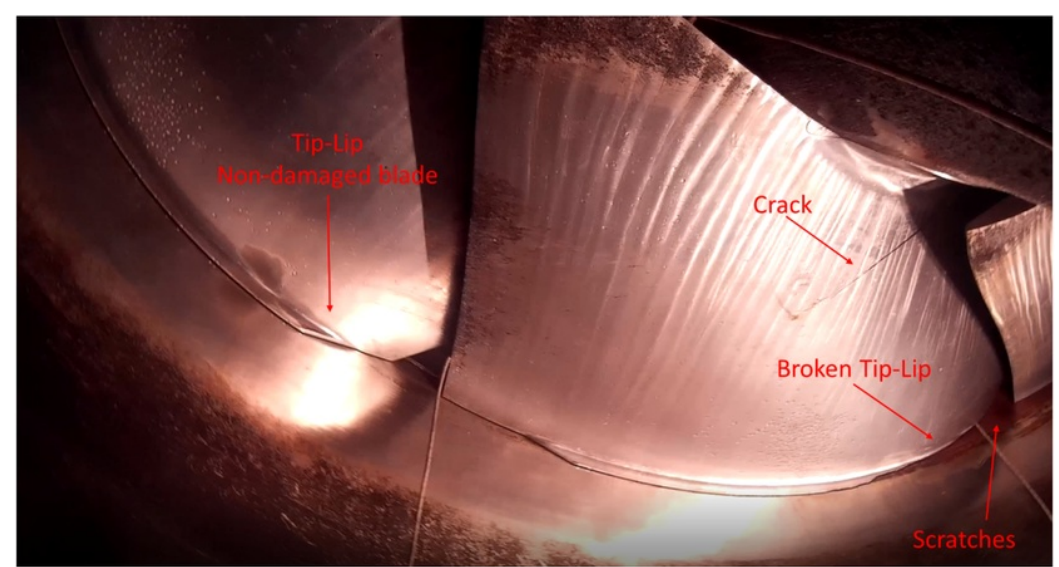

Fig. 4.Fiq. 4 View of the runner from below. Non-damaged blade (left) and damaged blade (right). alt-text: Fig. 4 


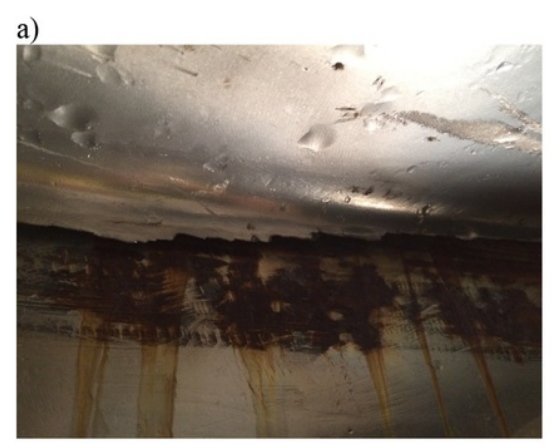

\section{b)}

Fig. 5,Fig. 5 Detail of the broken tip-lip and scratches in the stationary wall. a) Detail of the broken tip-lip. b) Detail of the scratches in the wall. alt-text: Fig. 5

\section{3. $\underline{3}$ Analysis of the machine vibration}

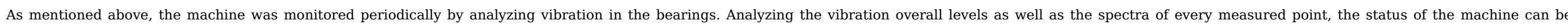
evaluated [19-21]. However, first, it is essential to understand the origin of the vibration in the turbine.

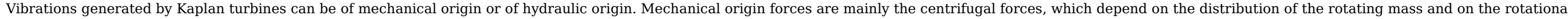

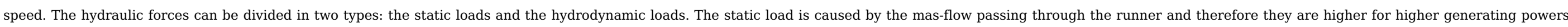

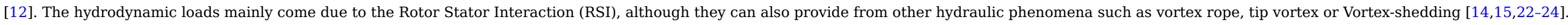

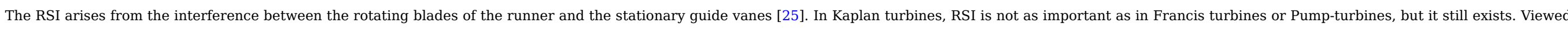
from the stationary frame, the RSI frequency depend on the rotating speed of the runner $\left(\mathrm{f}_{\mathrm{f}}\right)$, the number of rotating blades $\left(\mathrm{Z}_{\mathrm{b}}\right)$ and the order of harmonics $(\mathrm{n})$ : $f_{b, n}=n \cdot Z_{b} \cdot f_{f}$

The excitation shape corresponding every $f_{b, n}$ is the superposition of several excitation modes $(k)$ that can be calculated with the following expression: $\mathrm{k}=m \cdot Z_{v}-n \cdot Z_{b}$

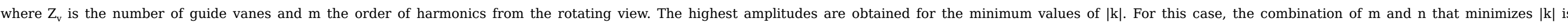

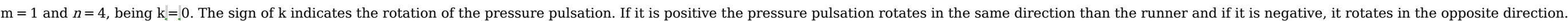

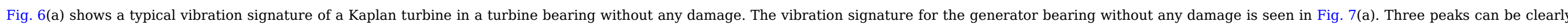

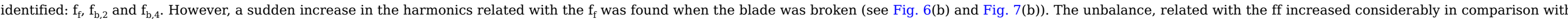

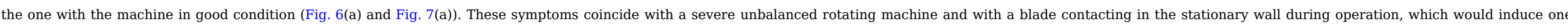
strong impact to the blade every revolution, exciting also the natural frequencies of the system. 

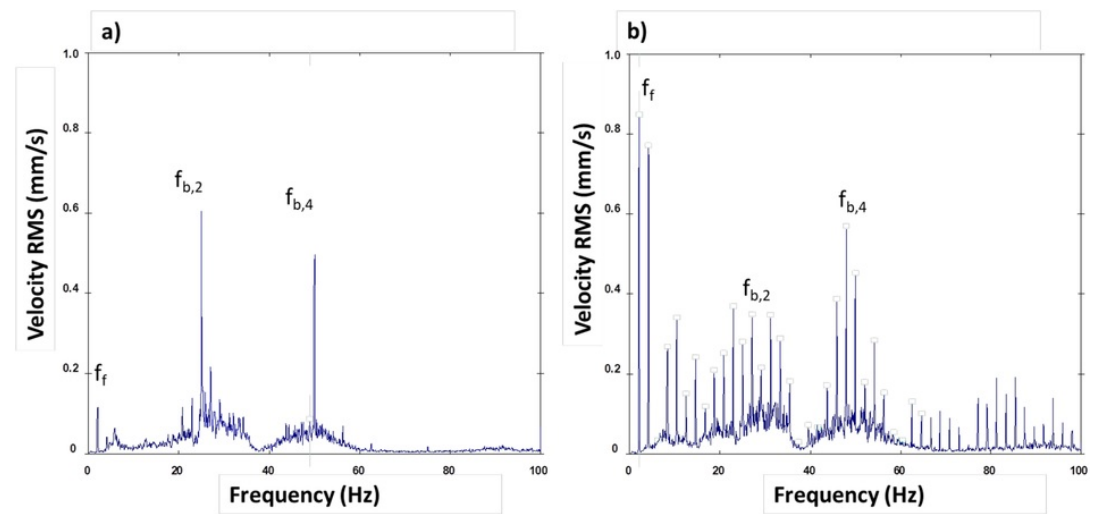

Fig. 6.Fig. 6 Comparison between the spectra before damage (a) and with damage (b). Turbine bearing alt-text: Fig. 6

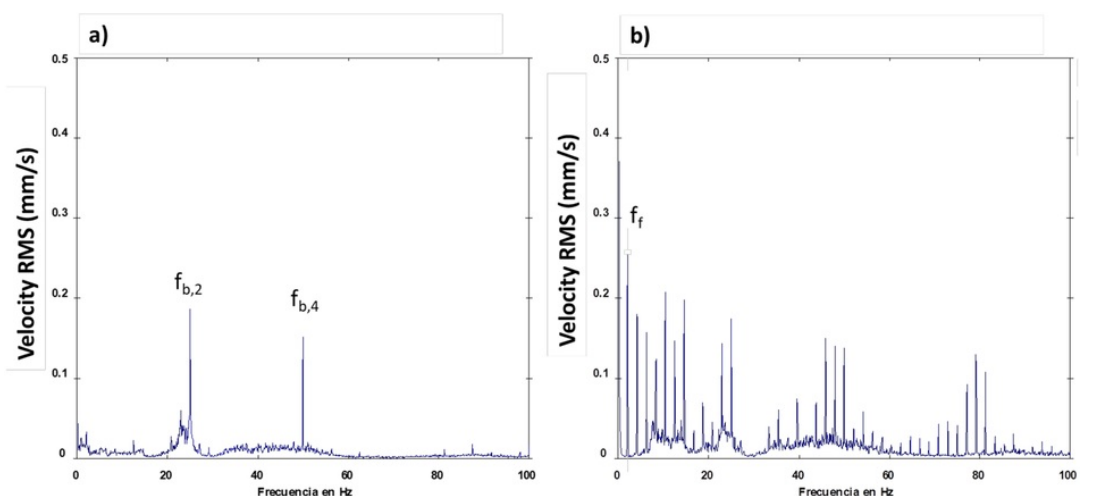

Fig. 7.Fig. 7 Comparison between the spectra before damage (a) and with damage (b). Generator bearing alt-text: Fig. 7

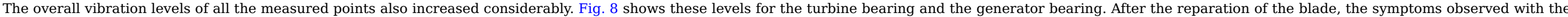
broken blade disappeared.
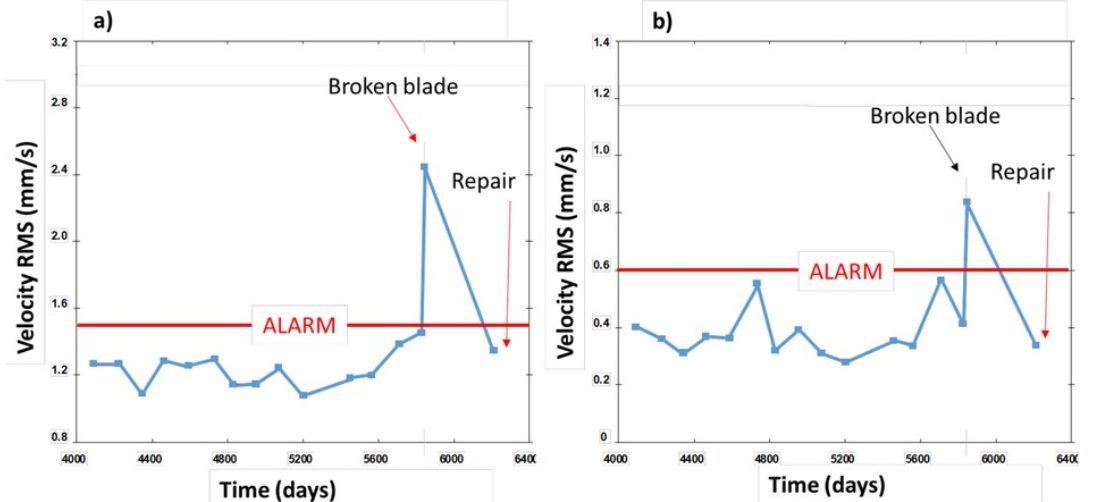


\section{alt-text: Fig. 8}

\section{4. $\underline{4}$ Numerical simulation}

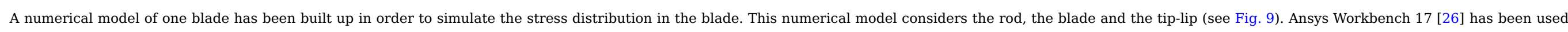

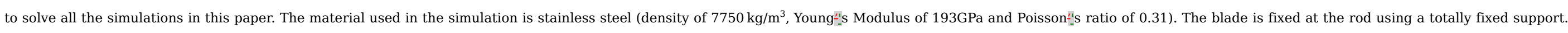

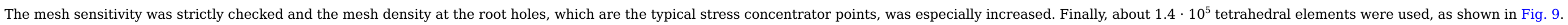

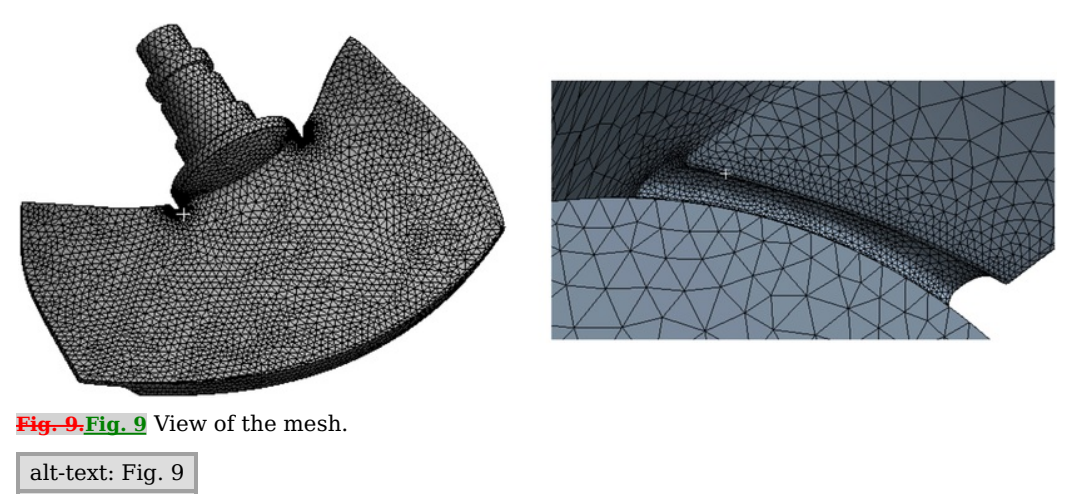

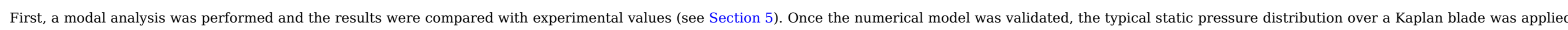

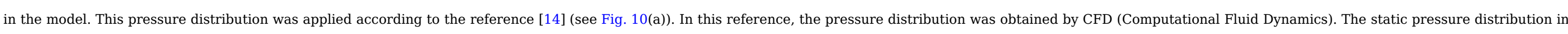

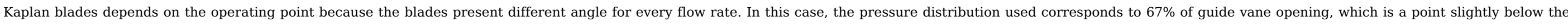

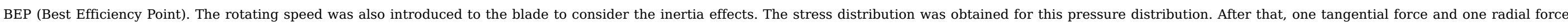

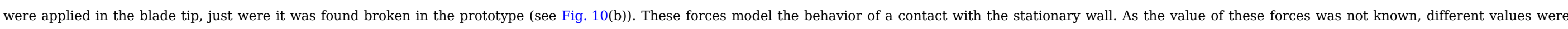
tested to see the influence of those forces on the stress distribution over the blade.

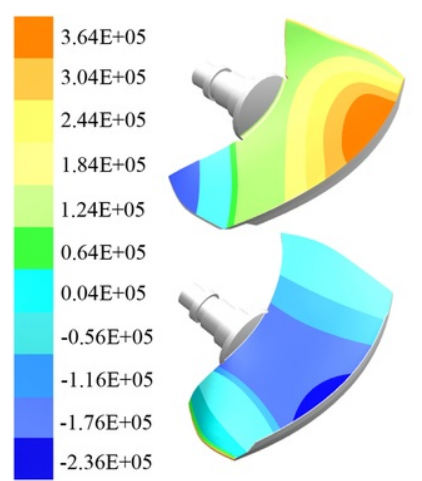

(a)

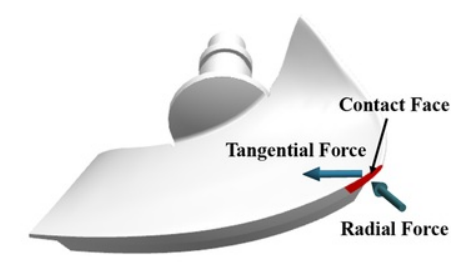

(b)

Fig. 10.Fiq. 10 Pressure pattern (unit: Pa)._b) Contact forces.

alt-text: Fig. 10

\section{5. $\underline{5}$ Experimental modal analysis}




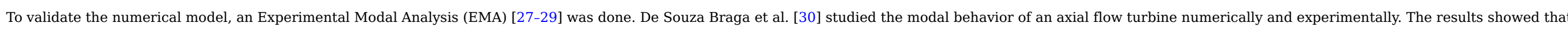
the blades:- mode-shapes are not affected between each other, therefore the modal behavior of the whole runner can be represented by the modal behavior of a single blade.

\subsubsection{Set-up and instrumentation}

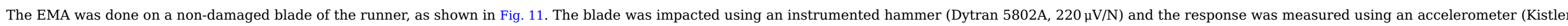

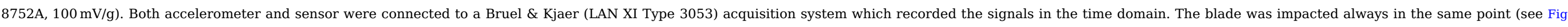

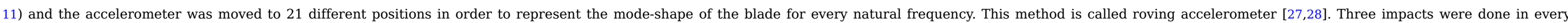
position of the accelerometer in order to compute the average of them. The positions where the accelerometer was placed are shown in Fig. 11.
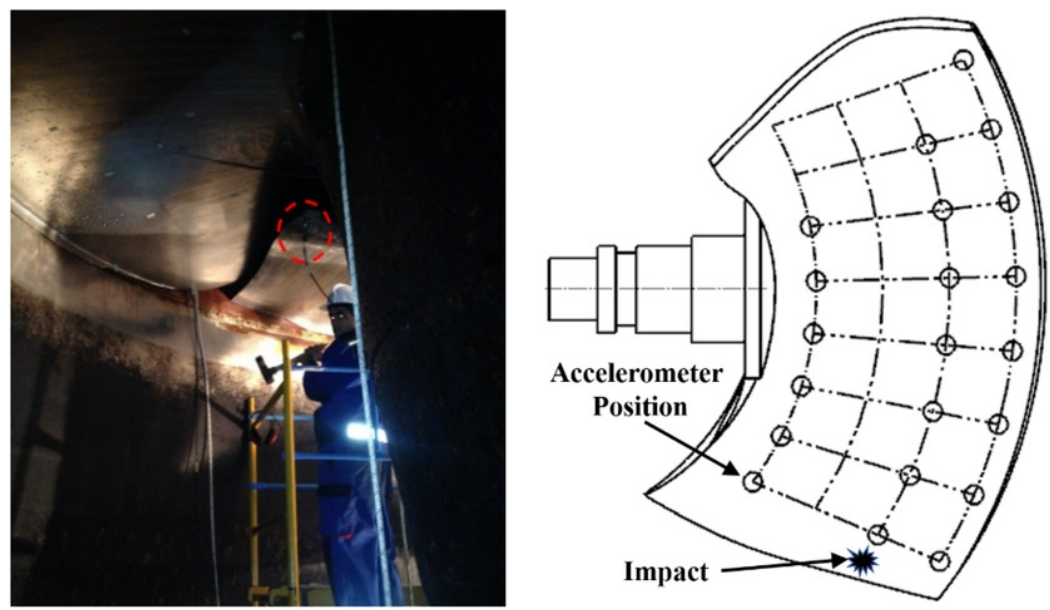

Eig. 11.Fiq. 11 Experimental Modal Analysis. Not include the radius, not necessary.

alt-text: Fig. 11

\subsubsection{Signal analysis}

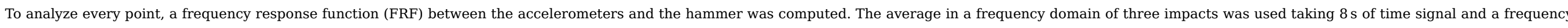

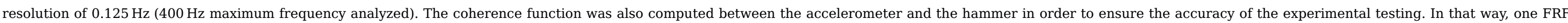
was obtained for every point where the accelerometer was located (21 in total). Using the 21 FRFs, an operational deflection shape (ODS) [28,31] of the runner can be obtained.

\subsubsection{Natural frequencies and mode-shapes}

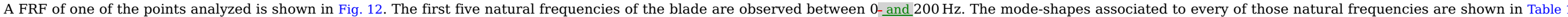

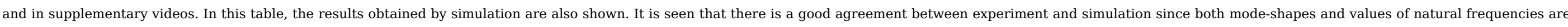
very close.

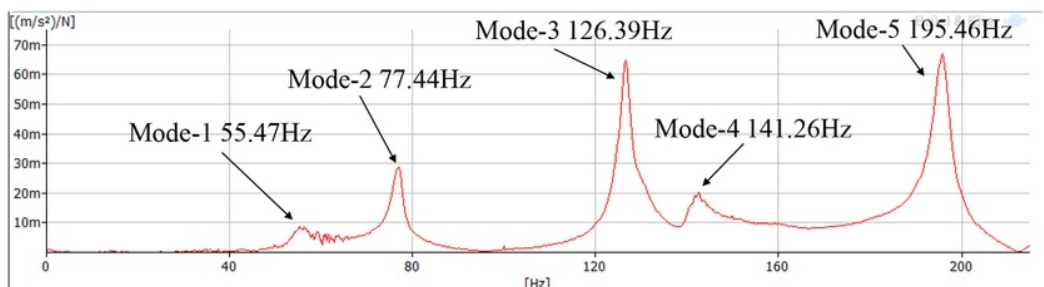


Table 1.Table 1 Experimental and numerical modes. Mode-shapes animations added as supplementary material.

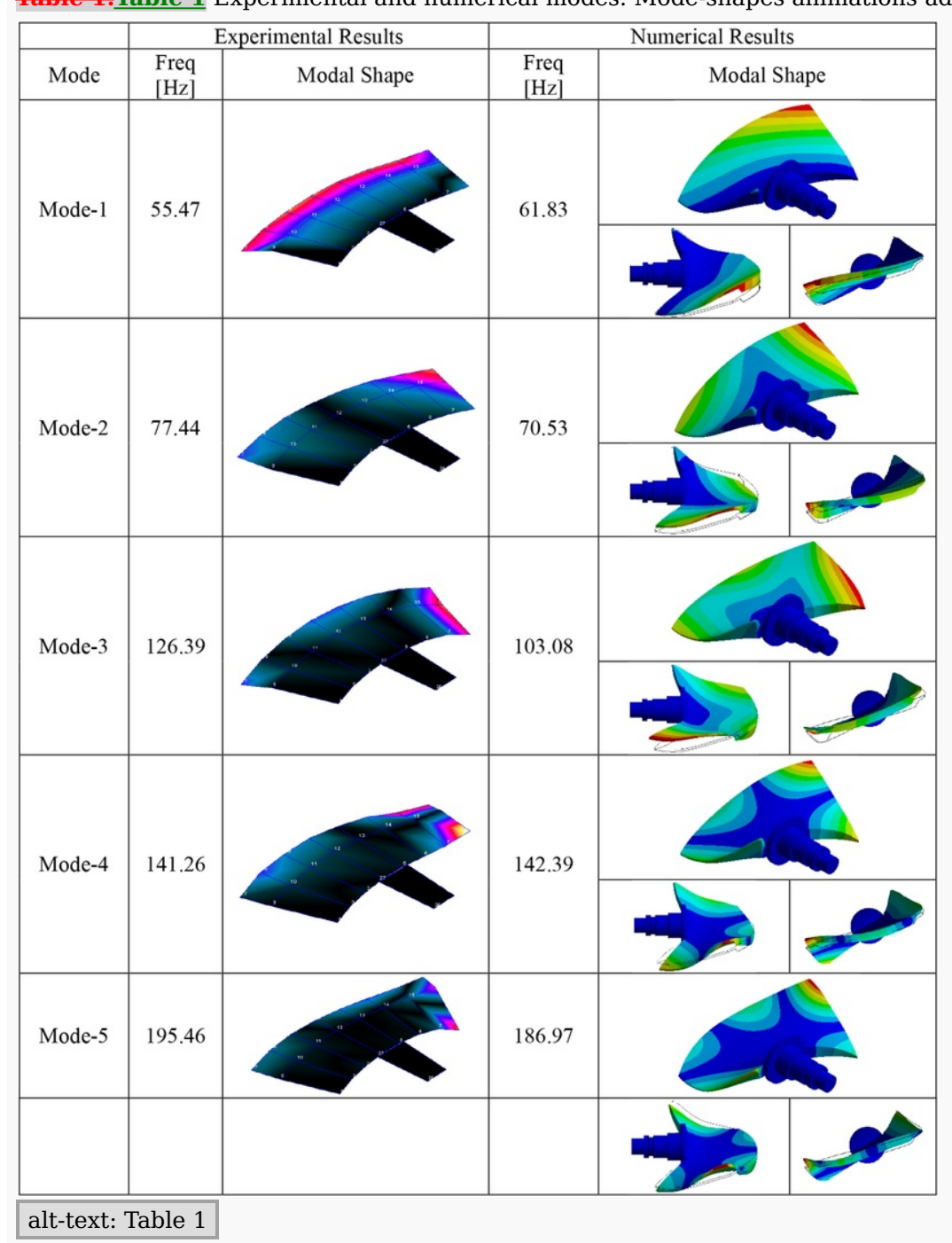

\subsection{Dynamic response of the blade}

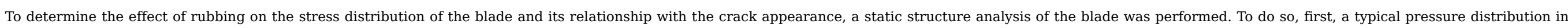
Kaplan turbines is applied to the structure as explained in Section 4 and then, a contact force was applied in the tip of the blade.

\subsubsection{Stress distribution under normal operating conditions}




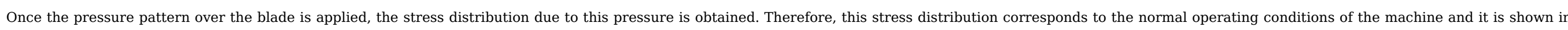

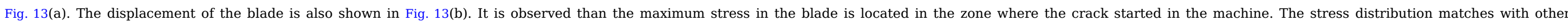
previously obtained in other Kaplan turbine prototypes [12].

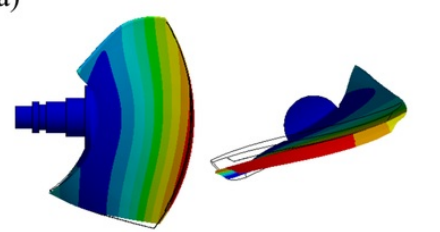

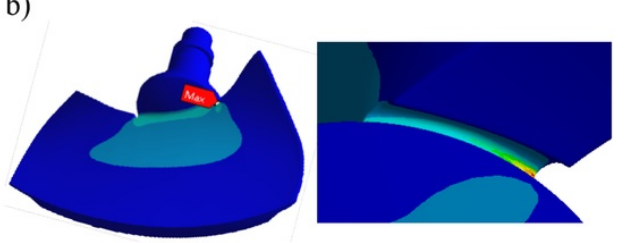

Eig. 13.Fig. 13 a) Displacement of the blade under normal operating conditions. b) Stress distribution under normal operating conditions.

alt-text: Fig. 13

\subsubsection{Stress distribution with rubbing}

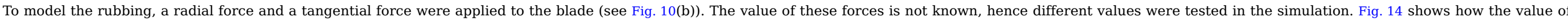

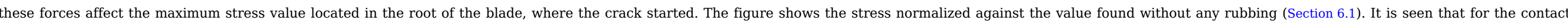

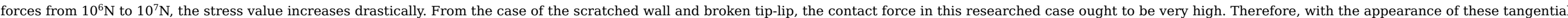
and radial forces the stress in the root increases and it demonstrates the appearance of the crack in the blade.

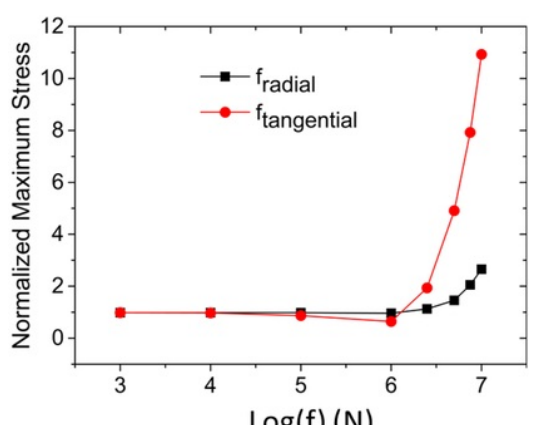

Fig. 14.Fig. 14 Normalized maximum stress changes with contact force.

alt-text: Fig. 14

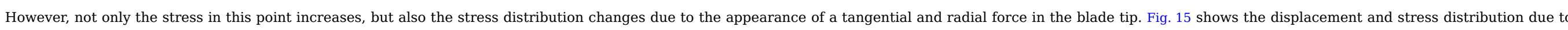

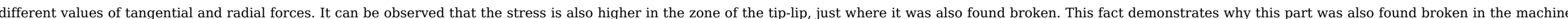
inspection. 


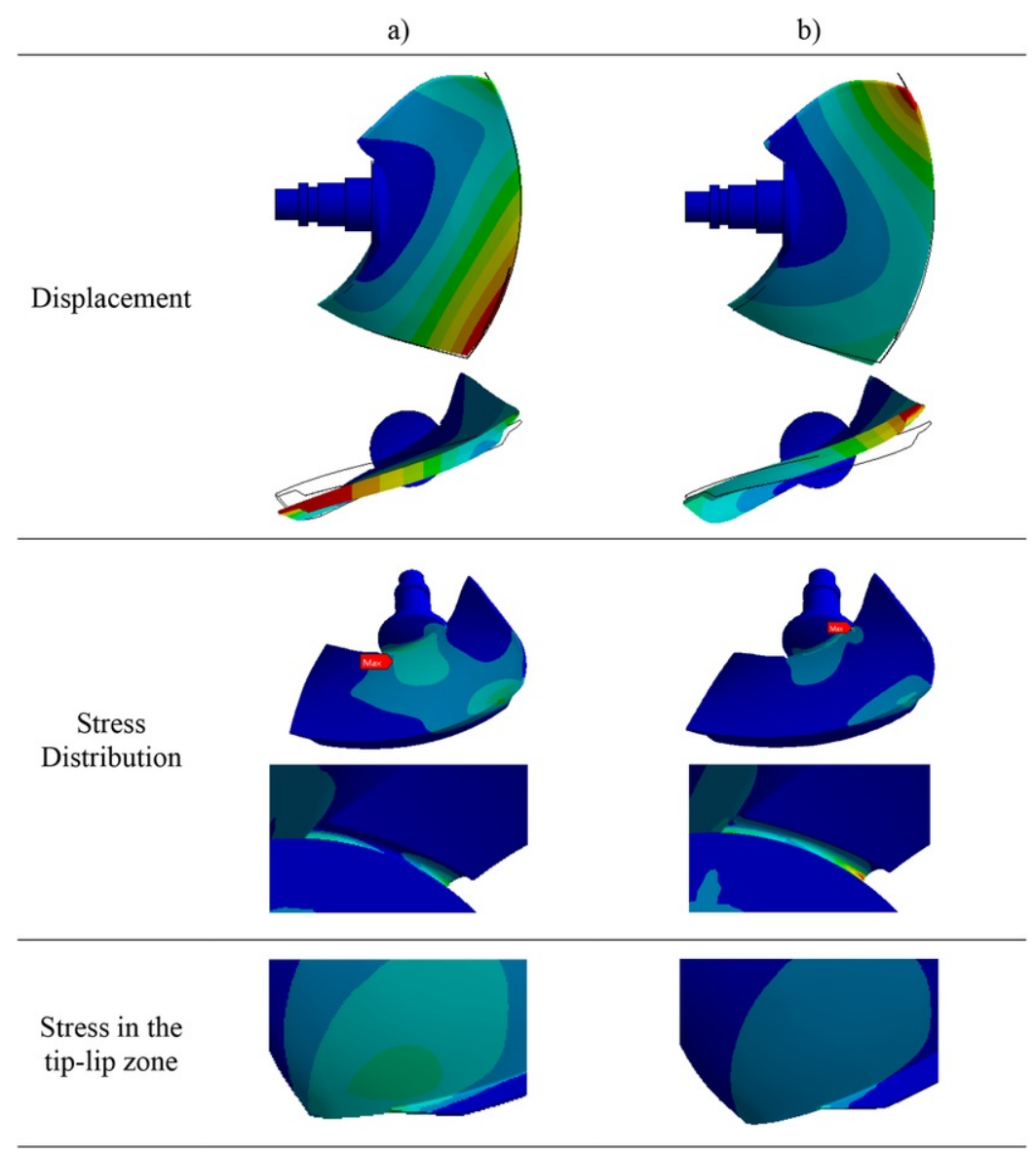

Fig. 15.Fig. 15 Displacement and stress distribution a) Tangential force value of $10^{6} \mathrm{~N}$. b) Radial force value of $10^{7} \mathrm{~N}$ alt-text: Fig. 15

\subsection{Conclusions}

In this paper, an uncommon failure of a Kaplan turbine blade has been analyzed to find out the causes that provoked it.

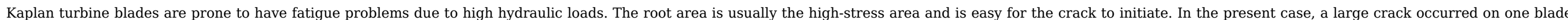
starting from the leading-edge side root hole. This damage generated an increase in the vibrations of the machine that was detected by the monitoring system.

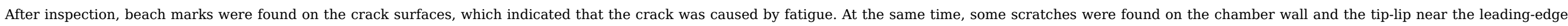
was broken. This showed that there had been a contact between the damaged blade and the wall.

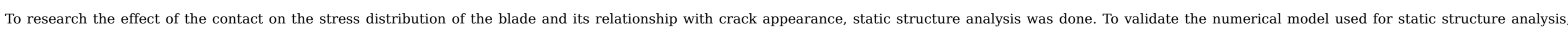
experimental modal analysis was done on an intact blade and the results showed that both the modes and their appearance sequences had good agreements with the numerical results.

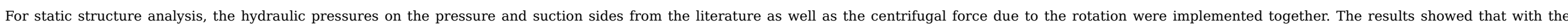

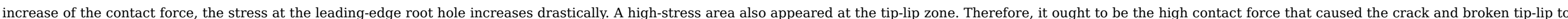


Supplementary data to this article can be found online at https://doi.org/10.1016/j.engfailanal.2019.01.056

\section{Acknowledgements}

The author wishes to acknowledge the contribution of ENDESA team to the development of this paper.

\section{References}

[1] E.E. Estevez, Comportament dinàmic de màquines hidràuliques, 2004, Univ. Politèc. de Catalunya.

[2] M.K. Padhy and R.P. Saini, A review on silt erosion in hydro turbines, Renew. Sustain. Energy Rew.Renew. Sust. Energ. Rev. 12, $2008,1974-1987$.

[3] D. Kumar and P.P. Bhingole, CFD based analysis of combined effect of cavitation and silt erosion on Kaplan turbine, Mater. Today Proc. 2, $2015,2314-2322$.

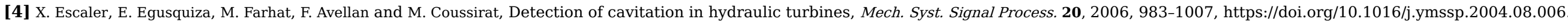

[5] L. Motycak, A. Skotak and R. Kupcik, Kaplan turbine tip vortex cavitation--analysis and prevention, In: IOP Conf. Ser. Earth Environ. SCi., $2012,32060$.

[6] P. Kumar and R.P. Saini, Study of cavitation in hydro turbines-Aa review, Rew. Sustain. Energy Rer.Renew. Sust. Energ. Rev 14, 2010, 374-383, https://doi.org/10.1016/j.rser.2009.07.024.

[7] Z.W. Wang, Y.Y. Luo, L.J. Zhou, R.F. Xiao and G.J. Peng, Computation of dynamic stresses in piston rods caused by unsteady hydraulic loads, Eng. Fail. Anal. 15, 2008 , 28-37.

[8] G. Urquiza, J.C. Garcia, J.G. Gonzalez, L. Castro, J.A. Rodriguez, M.A. Basurto-Pensado and O.F. Mendoza, Failure analysis of a hydraulic Kaplan turbine shaft, Eng. Fail. Anal. 41, $2014,108-117$.

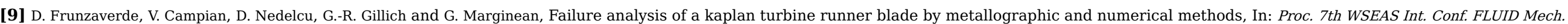
(FLUIDS'10), 2010, Univ. Cambridge, UK, 60-67.

[10] Y. Luo, Z. Wang, J. Zeng and J. Lin, Fatigue of piston rod caused by unsteady, unbalanced, unsynchronized blade torques in a Kaplan turbine, Eng. Fail. Anal. 17, 2010, 192-199.

[11] X. Liu, Y. Luo and Z. Wang, A review on fatigue damage mechanism in hydro turbines, Renew. Sustain. Energy Rer.Renew. Sust. Energ. Rev 54, 2016, 1-14.

[12] L. Zhou, Z. Wang, R. Xiao and Y. Luo, Analysis of dynamic stresses in Kaplan turbine blades, Eng. Comput. 24, 2007, 753-762.

[13] S. Liu, S. Li and Y. Wu, Pressure fluctuation prediction of a model Kaplan turbine by unsteady turbulent flow simulation, J. Fluids Eng. 131, 2009, 101102.

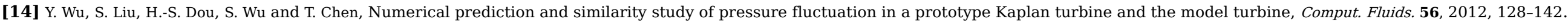

[15] L. Motycak, A. Skotak and J. Obrovsky, Analysis of the Kaplan turbine draft tube effect, In: IOP Conf. Ser. Earth Environ. Sci., $2010,12038$.

[16] X. Liu, A. Presas, Y. Luo and Z. Wang, Crack growth analysis and fatigue life estimation in the piston rod of a Kaplan hydro turbine, Fatigue Fract. Eng. Mater. Struct. 2018.

[17] F. Thiery, R. Gustavsson and J.-O. Aidanpää, Dynamics of a misaligned Kaplan turbine with blade-to-stator contacts, Int. J. Mech. Sci. 99, 2015, 251-261.

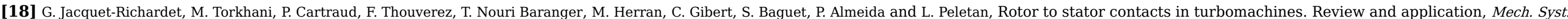
Signal Process. 40, 2013, 401-420, https://doi.org/10.1016/j.ymssp.2013.05.010.

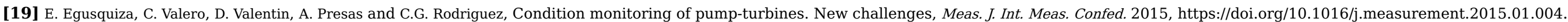

[20] M. Egusquiza, E. Egusquiza, C. Valero, A. Presas, D. Valentín and M. Bossio, Advanced condition monitoring of Pelton turbines, Measurement.Measurement 119, 2018, 46-55, https://doi.org/10.1016/j.measurement.2018.01.030.

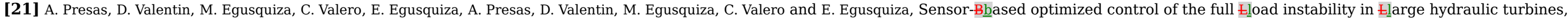


[22] B.G. Mulu, P.P. Jonsson and M.J. Cervantes, Experimental investigation of a Kaplan draft tube--Ppart I: Bbest efficiency point, Appl. Energy:Appl. Energy 93, 2012, 695-706.

[23] P.P. Jonsson, B.G. Mulu and M.J. Cervantes, Experimental investigation of a Kaplan draft tube--Part II: off-design conditions, Appl. Energy:Appl. Energy 94, 2012 , 71-83.

[24] K. Amiri, B. Mulu, M. Raisee and M.J. Cervantes, Load variation effects on the pressure fluctuations exerted on a Kaplan turbine runner, In: IOP Conf. Ser. Earth Environ. Sci, 2014 , 32005.

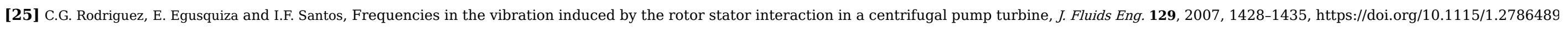

[26] ANSYS(R), Ansys User!-'s Manual 17.0, Canonsburg, Pennsylvania,USA2017.

[27] P. Avitabile, Experimental modal analysis, Sound Vib. 35, 2001, 20-31.

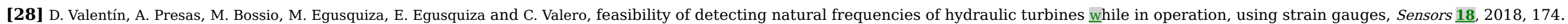

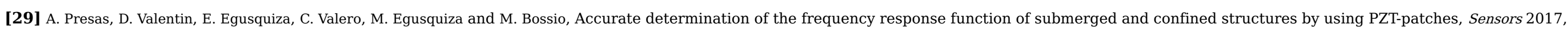
https://doi.org/10.3390/s17030660, (Switzerland).

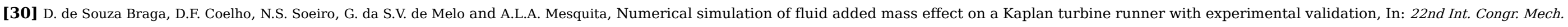
Eng. (COBEM 2013), 2013, 4331-4339.

[31] B.J. Schwarz and M.H. Richardson, Introduction to operating deflection shapes, CSI Reliab. Week. 10, 1999, 121-126.

\section{The following are the supplementary data related to this article.}

\section{Multimedia Component 1}

Supplementary video $\mathbf{S 1}$

alt-text: Supplementary video S1

Multimedia Component

Supplementary video $\mathbf{S 2}$

alt-text: Supplementary video S2

Multimedia Component

Supplementary video $\mathbf{S 3}$

alt-text: Supplementary video S3

Multimedia Component

Supplementary video S4

alt-text: Supplementary video S4

Multimedia Component

Supplementary video S5

alt-text: Supplementary video S5 
Multimedia Component 6

Supplementary video S6

alt-text: Supplementary video S6

Multimedia Component 7

Supplementary video $\mathbf{S 7}$

alt-text: Supplementary video S7

$\underline{\text { Multimedia Component } 8}$

Supplementary video S8

alt-text: Supplementary video S8

Multimedia Component 9

Supplementary video S9

alt-text: Supplementary video S9

Multimedia Component 10

Supplementary video S10

alt-text: Supplementary video S10

\section{Highlights}

- A large crack was discovered in a Kaplan turbine blade.

- A failure investigation of the crack was performed.

- Experimental research on the dynamic behavior of a Kaplan turbine blades was carried out.

- A numerical model of the Kaplan turbine blade was validated and used for studying the origin of the crack.

- Rubbing between the blade and the stationary wall was demonstrated to be the cause of the crack appearance.

\section{Queries and Answers}

Query:

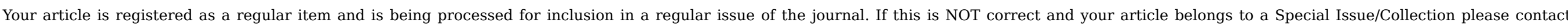
s.sadhasivan@elsevier.com immediately prior to returning your corrections.

\section{Answer: Yes}

Query: 
Please confirm that given names and surnames have been identified correctly and are presented in the desired order, and please carefully verify the spelling of all authors' names.

Answer: Yes

Query:

The author names have been tagged as given names and surnames (surnames are highlighted in teal color). Please confirm if they have been identified correctly.

Answer: Yes

Query:

Please check whether the designated corresponding author is correct, and amend if necessary.

Answer: Correct

Query:

Please provide caption for Supplementary video S1.

Answer: Mode 1. Experimental

Query:

Please provide caption for Supplementary video S2.

Answer: Mode 2. Experimental

Query:

Please provide caption for Supplementary video S3.

Answer: Mode 3. Experimental

Query:

Please provide caption for Supplementary video S4.

Answer: Mode 4. Experimental

Query:

Please provide caption for Supplementary video S5.

Answer: Mode 5. Experimental

Query:

Please provide caption for Supplementary video S6.

Answer: Mode 1. Numerical Simulation

Query:

Please provide caption for Supplementary video S7. 


\section{Answer: Mode 2. Numerical Simulation}

Query:

Please provide caption for Supplementary video S8.

Answer: Mode 3. Numerical Simulation

Query:

Please provide caption for Supplementary video S9.

Answer: Mode 4. Numerical Simulation

Query:

Please provide caption for Supplementary video S10.

Answer: Mode 5. Numerical Simulation

Query:

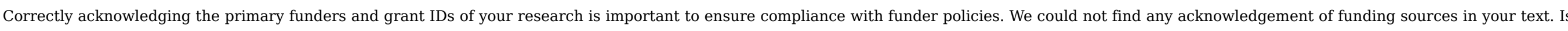
this correct?

Answer: Yes

Query:

Please provide the volume number and page range for the bibliography in Ref. [16].

Answer: Volume 41, Issue 11, pages 2402-2417 